\title{
IGF-1R associates with adverse outcomes after radical radiotherapy for prostate cancer
}

Tamara Aleksic ${ }^{1}$, Clare Verrill ${ }^{2,3}$, Richard J Bryant ${ }^{1,3}$, Cheng Han ${ }^{1,4}$, Andrew Ross Worrall ${ }^{1}$, Laurent Brureau ${ }^{3,5}$, Stephane Larré ${ }^{3,6}$, Geoff S Higgins ${ }^{1,4}$, Fahad Fazal ${ }^{4}$, Ahmad Sabbagh ${ }^{4}$, Syed Haider ${ }^{1,7}$, Francesca M Buffa ${ }^{1}$, David Cole ${ }^{4,8}$ and Valentine M Macaulay ${ }^{\star 1,4}$

${ }^{1}$ Department of Oncology, University of Oxford, Old Road Campus Research Building, Roosevelt Drive, Oxford OX3 7DQ, UK; ${ }^{2}$ Department of Cellular Pathology, Oxford University Hospitals NHS Foundation Trust, John Radcliffe Hospital, Oxford OX3 9DU UK; ${ }^{3}$ Nuffield Department of Surgical Sciences, University of Oxford, John Radcliffe Hospital, Oxford OX3 9DU, UK and ${ }^{4}$ Oxford Cancer and Haematology Centre, Oxford University Hospitals NHS Foundation Trust, Churchill Hospital, Oxford OX3 7LJ, UK

Background: Activated type 1 insulin-like growth factor receptors (IGF-1Rs) undergo internalisation and nuclear translocation, promoting cell survival. We previously reported that IGF-1R inhibition delays DNA damage repair, sensitising prostate cancer cells to ionising radiation. Here we tested the clinical relevance of these findings.

Methods: We assessed associations between IGF-1R and clinical outcomes by immunohistochemistry in diagnostic biopsies of 136 men treated with 55-70Gy external beam radiotherapy for prostate cancer, comparing results with publicly available transcriptional data in surgically treated patients.

Results: Following radiotherapy, overall recurrence-free survival was shorter in patients whose tumours contained high total, cytoplasmic and internalised (nuclear/cytoplasmic) IGF-1R. High total IGF-1R associated with high primary Gleason grade and risk of metastasis, and cytoplasmic and internalised IGF-1R with biochemical recurrence, which includes patients experiencing local recurrence within the radiation field indicating radioresistance. In multivariate analysis, cytoplasmic, internalised and total IGF-1R were independently associated with risk of overall recurrence, and cytoplasmic IGF-1R was an independent predictor of biochemical recurrence post radiotherapy. Insulin-like growth factor receptors expression did not associate with biochemical recurrence after radical prostatectomy.

Conclusions: These data reveal increased risk of post-radiotherapy recurrence in men whose prostate cancers contain high levels of total or cytoplasmic IGF-1R.

Insulin-like growth factors (IGFs) bind to type 1 IGF receptors (IGF-1Rs) on the surface of most cells, activating signalling effectors, including AKT, to promote normal embryonic and postnatal development (Baker et al, 1993). In tumours, IGF-1R signalling mediates proliferation, invasion and cell survival via protection from apoptosis (Chitnis et al, 2008). Activated IGF-1Rs undergo internalisation, and are then degraded or recycled back to the plasma membrane (Goh and Sorkin, 2013). We and others reported that some activated internalised IGF-1Rs translocate to the nucleus of human tumour cells, influencing gene expression (Aleksic et al, 2010; Sehat et al, 2010; Sarfstein et al, 2012; Warsito et al, 2012).

*Correspondence: Dr VM Macaulay; E-mail: valentine.macaulay@oncology.ox.ac.uk

${ }^{5}$ Current address: Pointe-à-Pitre University Hospital, Pointe-à-Pitre, Guadeloupe, France.

${ }^{6}$ Current address: Centre Hospitalier Universitaire de Reims, Hôpital Robert Debré, 51092 Reims, France.

${ }^{7}$ Current address: Breast Cancer Now Toby Robins Research Centre, Institute of Cancer Research, London SW3 6JB, UK.

${ }^{8}$ Current address: Genesis Care Oxford, Peters Way, Oxford, OX4 6LB, UK.

Received 4 June 2017; revised 20 July 2017; accepted 30 August 2017; published online 3 October 2017

(C) 2017 Cancer Research UK. All rights reserved 0007-0920/17 
The IGF axis is recognised as mediating resistance to anticancer therapies (King et al, 2014). The first report linking IGF-1R with radioresistance came from a study of breast cancer patients, where IGF-1R overexpression was associated with early recurrence within the irradiated site (Turner et al, 1997). High IGF-1R also associates with radioresistance in cervical cancer (Lloret et al, 2007), and we reported that IGF-1R is overexpressed in HPV-negative head and neck cancers that are characterised by resistance to chemoradiation (Dale et al, 2015). Preclinical data support a link with radioresistance: we and others showed that IGF-1R targeting enhances chemo- and radiosensitivity in a range of tumour models in vitro and in vivo, independent of apoptosis induction (Macaulay et al, 2001; Tezuka et al, 2001; Cosaceanu et al, 2007; Isebaert et al, 2011; Riesterer et al, 2011). Subsequently, we reported that IGF-1R depletion or inhibition enhances the sensitivity of prostate cancer cells to ionising radiation (IR). This effect was associated with delayed resolution of IR-induced DNA double-strand breaks (DSBs) and inhibition of DSB repair by both non-homologous end-joining and homologous recombination (Turney et al, 2012; Chitnis et al, 2014). The aim of the current study was to investigate whether these findings have clinical relevance, by assessing IGF-1R expression in prostate cancers of men treated with radical radiotherapy. Our major findings are first that patients whose tumours express high total IGF-1R experience adverse outcomes, including increased risk of overall and metastatic relapse. Second, high internalised IGF-1R associates significantly with increased risk of biochemical relapse. This group includes patients experiencing recurrence within the irradiated field, supporting a link with clinical radioresistance.

\section{MATERIALS AND METHODS}

Clinical cases. Clinical data were extracted from records of patients treated with external beam radiotherapy in Oxford from 2000 to 2005, including age, date of diagnosis, presenting PSA, clinical tumour (cT) stage, Gleason grade and Gleason Sum score. Using follow-up data, including serial PSA monitoring, isotope bone scans, CT scans, MRI and PET-CT scans, patients were assigned to one of three groups: long-term remission, metastatic relapse, or biochemical relapse. The latter was defined using the ASTRO-Phoenix Consensus criteria (Roach et al, 2006) as $+2 \mathrm{ng} \mathrm{ml}^{-1}$ PSA rise above the post-radiotherapy nadir, without evidence of metastatic disease. This study was approved by the National Research Ethics Service (07/H0606/120).

Type 1 IGF receptor immunohistochemistry. Archival diagnostic formalin-fixed paraffin-embedded (FFPE) prostate biopsies were selected for this study. Routinely, left- and right-sided biopsies had been embedded in separate blocks, $\leqslant 6$ biopsies per block. For patients with unilateral tumour, the ipsilateral (i.e., cancer-containing) block was selected for study. For cases with bilateral tumour, the block selected was the most representative of Gleason grade. The chosen tumour-containing blocks were used for IGF-1R immunohistochemistry (IHC) as described (Aleksic et al, 2016). For details of method and scoring see Supplementary Information. In brief, IGF-1R signal in $\leqslant 6$ biopsies per case was scored blinded by uro-pathologist CV for intensity (0-3) and percentage positivity $(0-4)$ in the malignant prostatic epithelium. This generated immunoreactive scores (intensity $\times$ percentage, range 0-12) for membrane, cytoplasmic and nuclear IGF-1R. Internalised IGF-1R (0-24) was represented by the sum of cytoplasmic and nuclear IGF-1R, and total IGF-1R (0-36) as the sum of membrane, cytoplasmic and nuclear IGF-1R. Where present, benign prostatic epithelium was also scored for IGF-1R content.
Statistical analysis. Clinical data were analysed using $t$-tests and Wilcoxon matched-pairs signed rank test for non-parametric data. The IGF-1R IHC scores were binarised by the median score and analysed as categorical variables by $\chi^{2}$-test. Overall survival (OS) was defined as the follow-up time from radiotherapy until death. Patients not reported as dead were censored at their last known date alive. Recurrence-free survival (RFS) was defined as time from radiotherapy until any recurrence (biochemical or metastatic). Recurrence-free survival data are displayed using Kaplan-Meier curves, with the associated log-rank (Mantel-Cox) test. Cox proportional hazards models were fitted for IGF-1R for RFS and OS in both univariate and multivariate analyses. IGF1R expression data were extracted from (Taylor et al, 2010) and analysed for association with risk of biochemical recurrence by Wald test. Statistical analysis was performed using GraphPad Prism v6, STATA 11.2 (Stata Corporation, College Station, TX, USA) and R Statistical programming environment (v3.2.4, R package: survival v2.38-3. R Core Team: Vienna, Austria). All statistical tests were two-sided, and $P<0.05$ was considered significant.

\section{RESULTS}

From a database of $\sim 800$ prostate cancer patients treated with radical radiotherapy from 2000 to 2005, we identified 136 with available FFPE tissue (Table 1), and in whom we could ascertain outcomes of remission (75 cases), metastatic recurrence (17) or biochemical recurrence (44) from imaging and serial PSAs. External beam radiotherapy had been 3D conformal CT planned, and treatment typically involved delivering a $55 \mathrm{~Gy}$ dose to the planning target volume in 20 fractions over 4 weeks (Table 1 ). Assuming an $\alpha / \beta$ ratio for prostate cancer of $1.8 \mathrm{~Gy}$ (Dearnaley et al, 2016), this dose/fractionation schedule is equivalent to $65.9 \mathrm{~Gy}$ in $2 \mathrm{~Gy}$ fractions. Radiotherapy was administered to all other patients in fractions of $2 \mathrm{~Gy}$. Of the 136 patients, 57 (42\%) had also received adjuvant endocrine therapy, generally for 6-48 months (Table 1). Median follow-up was 7.86 years (range $0.46-12.68$ years). To assess the extent to which this cohort is representative, we assessed associations of adverse outcome with the principal prognostic factors: primary Gleason grade, stage, and presenting PSA (Heidenreich et al, 2014). Univariate analysis confirmed significant associations between risk of overall recurrence and Gleason grade (primary grade 4 vs 3 ), stage ( 1 vs 2 or 3 ) and PSA $10-20 v s<10$, although increased risk in patients with PSA $\geqslant 20$ did not reach significance (Supplementary Table S1). Adjuvant endocrine therapy has been shown to improve diseasefree survival and OS following radiotherapy for localised prostate cancer (Kumar et al, 2006; Bolla et al, 2010), but was associated with increased risk of overall recurrence in our series (Supplementary Figure S1A). This likely reflects the practice during 2000-2005 of offering endocrine therapy only to high-risk patients. Indeed, those receiving endocrine therapy had highergrade tumours (median primary Gleason grade $4 v s$ ) and a lower proportion of stage cT1 tumours ( 15 out of $57,26 \%$ vs 30 out of 79 , $38 \%$ ) compared with patients not offered endocrine therapy.

We then evaluated the IGF-1R content of the prostate biopsies, detecting IGF-1R in 109 out of $136(80.1 \%)$ of the cancers with variable subcellular localisation in the plasma membrane, cytoplasm and nuclei (Table 2; Figure 1A). All but 8 biopsies contained benign prostatic epithelium, of which 90 out of $128(70.3 \%)$ contained detectable IGF-1R. Compared with benign glands from the same biopsies, IGF-1R expression was higher in the malignant prostatic epithelium $(P<0.001$; Figure 1B), confirming our previous report of IGF-1R overexpression in primary prostate cancer (Hellawell et al, 2002). The expression of IGF-1R did not associate with $\mathrm{cT}$ stage or presenting PSA, but higher-grade 
Table 1. Demographic data

\begin{tabular}{|c|c|}
\hline Median (range) & Patients, N (\%) \\
\hline \multicolumn{2}{|l|}{ Age } \\
\hline $69(55-79)$ & 136 \\
\hline \multicolumn{2}{|l|}{ PSA } \\
\hline \multicolumn{2}{|l|}{$13.0(1.3-414)$} \\
\hline \multicolumn{2}{|l|}{ Primary Gleason grade } \\
\hline 3 & 74 \\
\hline 4 & 61 \\
\hline 5 & 1 \\
\hline \multicolumn{2}{|l|}{ cT stage } \\
\hline cT1 & 45 \\
\hline cT2 & 58 \\
\hline ст3а & 28 \\
\hline \multicolumn{2}{|l|}{ Radiotherapy } \\
\hline $55 \mathrm{~Gy}$ in 20 fractions & 120 \\
\hline $64 \mathrm{~Gy}$ in 32 fractions & 6 \\
\hline $68 \mathrm{~Gy}$ in 34 fractions & 1 \\
\hline 70 Gy in 35 fractions & 9 \\
\hline \multicolumn{2}{|c|}{ Adjuvant endocrine therapy } \\
\hline Goserelin plus bicalutamide & 57 \\
\hline \multicolumn{2}{|l|}{ Outcome } \\
\hline Remission & 75 \\
\hline Relapse & 61 \\
\hline Metastatic recurrence & 17 \\
\hline Biochemical recurrence & 44 \\
\hline Death & 26 \\
\hline \multicolumn{2}{|l|}{ Cancer IGF-1R } \\
\hline Positive & $109(80.1)$ \\
\hline Membrane & $77(56.6)$ \\
\hline Cytoplasm & $86(63.2)$ \\
\hline Nuclear & $37(27.2)$ \\
\hline Internalised & $96(70.6)$ \\
\hline Membrane only & $13(9.6)$ \\
\hline Negative & $27(19.9)$ \\
\hline \multicolumn{2}{|c|}{$\begin{array}{l}\text { Abbreviations: cT stage = clinical tumour stage at presentation; IGF-1R=type } 1 \text { insulin-like } \\
\text { growth factor receptor; PSA = prostate-specific antigen. Demographic data of patients } \\
\text { treated with radical radiotherapy for prostate cancer. Adjuvant endocrine therapy was } \\
\text { administered concurrently and for median } 6 \text { months post radiotherapy; only } 4 \text { patients had } \\
<6 \text { months endocrine therapy (range } 2-48 \text { months). Table also shows number (\%) of } \\
\text { tumours containing detectable IGF-1R overall and in each subcellular compartment. }\end{array}$} \\
\hline
\end{tabular}

\section{Table 2. Association of IGF-1R with clinical factors}

\begin{tabular}{|l|c|c|c|}
\cline { 2 - 3 } \multicolumn{1}{c|}{} & \multicolumn{2}{c|}{ Total IGF-1R } \\
\cline { 2 - 3 } \multicolumn{1}{c|}{} & IGF-1R $\leqslant \mathbf{8}$ & IGF-1R $>\mathbf{8}$ & $\boldsymbol{P}$-value \\
\hline Clinical stage & 31 & 14 & 0.260 \\
\hline CT1 & 37 & 21 & \\
CT2 & 14 & 14 & \\
CT3 & &
\end{tabular}

\section{Primary Gleason grade}

\begin{tabular}{|l|l|l|l|}
\hline Gleason 3 & 53 & 19 & 0.004 \\
Gleason $\geqslant 4$ & 31 & 32 & \\
\hline PSA & 32 & 14 & 0.289 \\
\hline $0-10$ & 28 & 19 & \\
$10-20$ & 19 & 17 & \\
$>20$ &
\end{tabular}

Abbreviations: $\mathrm{cT}$ stage $=$ clinical tumour stage at presentation; IGF-1R $=$ type 1 insulin-like growth factor receptor; PSA $=$ prostate-specific antigen. $\chi^{2}$-test was used to test for differences in stage, Gleason score and PSA between high and low IGF-1R groups. There was significant association between total IGF-1R and Gleason grade, with higher-grade tumours (primary Gleason grade $\geqslant 4$ ) containing more IGF-1R than tumours with primary Gleason grade 3. There were no significant associations between cT stage or Gleason grade and IGF-1R scores in the plasma membrane, cytoplasm or nucleus, or with internalised (cytoplasmic plus nuclear) IGF-1R. tumours (primary Gleason grade 4-5) contained significantly more IGF-1R than lower-grade tumours (primary Gleason grade 3, $P=0.004$; Table 2).

Using Kaplan-Meier and univariate analyses, we tested for associations between clinical outcomes and IGF-1R expression and subcellular localisation. The risk of overall recurrence was significantly greater in men whose prostate cancers contained high total IGF-1R. There were also significant associations between overall recurrence and cytoplasmic or internalised (nuclear plus cytoplasmic) IGF-1R (Table 3; Figure 1C). Analysis of membrane and nuclear IGF-1R separately showed no significant association with outcome (Table 3). Of the 136 patients, 17 (12.5\%) developed scan-confirmed metastatic disease, which associated significantly with high total IGF-1R (Table 3; Figure 1D). We also assessed associations with OS, as 26 out of 136 (19\%) of the cohort had died, finding borderline association between risk of death and high total IGF-1R $(P=0.059$; Table 3$)$. Neither cytoplasmic nor internalised IGF-1Rs were associated with metastatic disease or OS (Table 3; Supplementary Figure 1B).

Biochemical recurrence was experienced by 44 (32\%) patients, comparable with reported biochemical failure rates of $26-40 \%$ for low/intermediate risk disease and up to $70 \%$ for high-risk disease following radical external beam radiotherapy (Grossfeld et al, 2002; Morgan et al, 2007; Gabriele et al, 2016; Zargar et al, 2017). Biochemical recurrence showed borderline association with total IGF-1R ( $P=0.059$ by univariate analysis, Table $3 ; P=0.055$ by Kaplan-Meier analysis, Supplementary Figure S1C). Analysing IGF-1R scores by subcellular compartment (Table 3; Figure 1E), we identified significant associations between biochemical recurrence and IGF-1R in the cytoplasmic ( $P=0.002$ by univariate analysis and 0.001 by Kaplan-Meier) or internalised (nuclear plus cytoplasmic; $P=0.034$ and 0.031 , respectively) compartments. Patients experiencing biochemical recurrence include those with occult metastases and patients experiencing local recurrence within the radiation field. It is not possible to differentiate these two outcomes with certainty, because routine prostate biopsies are not performed in this situation (Morgan et al, 2007), and none of these patients underwent salvage prostatectomy. However, it is estimated that $\geqslant 30 \%$ of post-irradiation biochemical recurrences are due to local recurrence, which is an indicator of clinical radioresistance (Bolla et al, 2010). In an attempt to further test associations of IGF$1 \mathrm{R}$ with local recurrence, we repeated the Kaplan-Meier analyses after excluding patients $(n=5)$ who experienced scan-confirmed metastatic recurrence within 2 years, and were therefore likely to have had occult metastases at the time of radiotherapy. This had no effect on the significance of associations identified between risk of biochemical recurrence and high cytoplasmic $(P=0.001$, unchanged), internalised ( $P=0.030$ with 5 cases excluded and $P=0.031$ for all 136 cases $)$ or total IGF-1R $(P=0.055$, unchanged; Supplementary Figure 1D).

Using multivariate analysis, tumour stage was independently associated with overall and biochemical recurrence (Table 4), as is predictable (Heidenreich et al, 2014), although this effect was apparent only when comparing clinical stage cT2 (not cT3) with cT1. Importantly, cytoplasmic, internalised and total IGF-1Rs were independent predictors of overall recurrence. Furthermore, cytoplasmic IGF-1R and stage (cT1 vs 2) were the only factors independently associated with the risk of biochemical recurrence (Table 4; Supplementary Table S2). In this cohort, primary Gleason grade $(3 v s \geqslant 4)$ was not independently associated with overall or biochemical recurrence, but was the only factor independently predictive of metastatic recurrence (Table 4; Supplementary Table S2).

Finally, we utilised publically available data to test for associations between IGF-1R and outcome in men with prostate cancer treated by radical prostatectomy. Excluding 37 patients who had received previous radiotherapy, the cohort of Taylor et al 

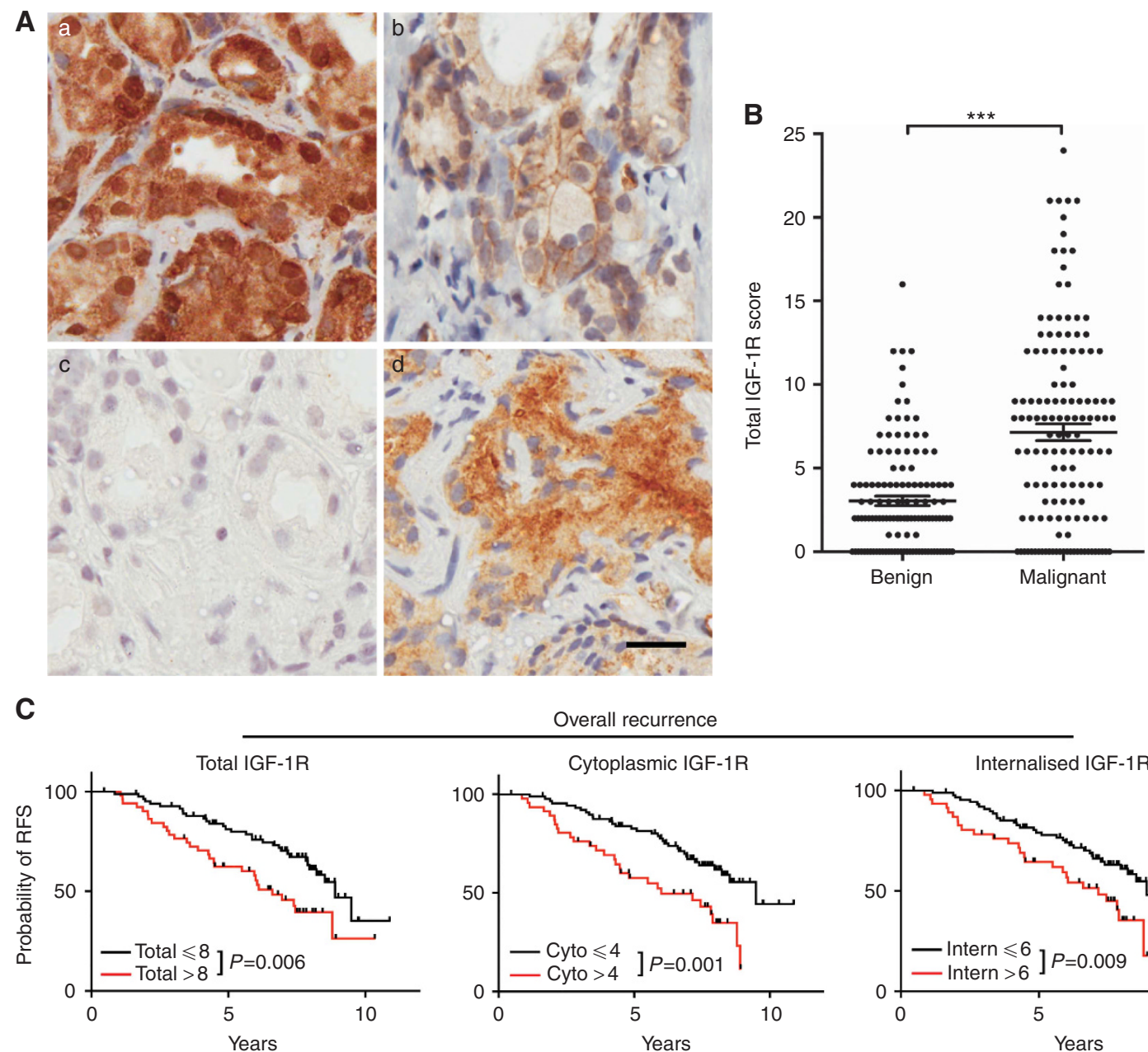

Overall recurrence
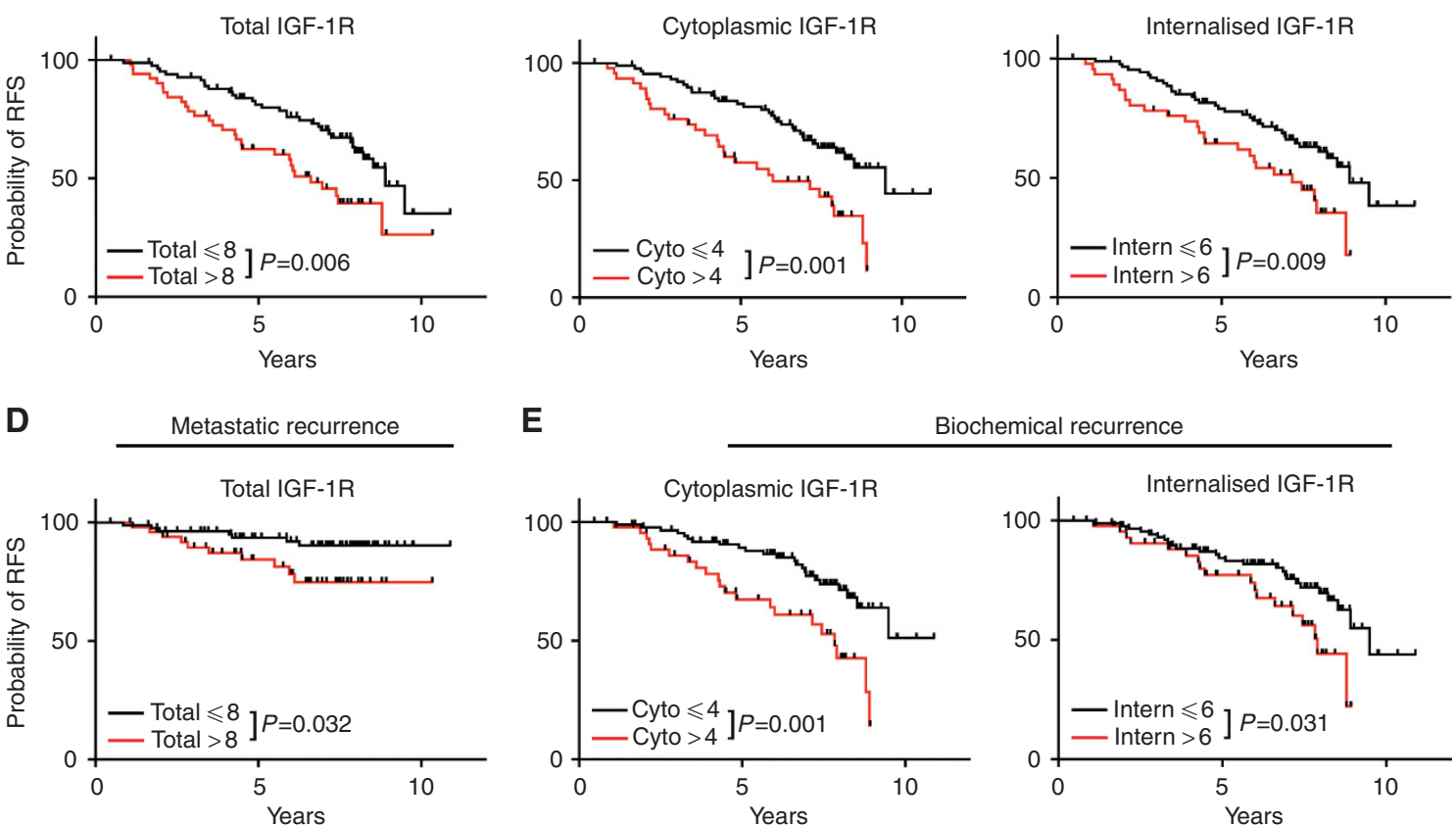

Biochemical recurrence

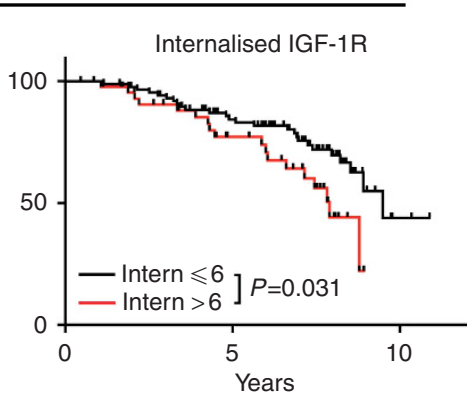

Figure 1. Type 1 IGF receptor associates with adverse outcomes in patients treated with radical radiotherapy for prostate cancer. (A) Examples of IGF-1R IHC in diagnostic biopsies of prostate cancer from patients treated with radiotherapy. (a) Gleason $3+4=7$ cancer, IGF-1R score membrane 0, cytoplasm 12, nuclear 9; (b) Gleason 4+3=7 cancer, IGF-1R score membrane 6, cytoplasm 3, nuclear 0; (c) Gleason $3+3=6$ cancer containing no detectable IGF-1R; (d) Gleason $4+5=9$ cancer, IGF-1R score membrane 0, cytoplasm 12, nuclear 0. Scale bar, $20 \mu$ m. (B) Total IGF$1 \mathrm{R}$ score (bars, mean \pm s.e.m.) in benign and malignant areas (*** $P=0.001$ by Wilcoxon matched-pairs signed rank test). (C-E) Kaplan-Meier plots with log-rank (Mantel-Cox) tests to assess association of total, cytoplasmic (Cyto) and internalised (Intern) IGF-1R with (C) all recurrences, (D) metastatic recurrence and (E) biochemical recurrence.

(2010) included 103 patients with microarray data on IGF1R expression, and clinical data on biochemical recurrence. In this surgical data set there was no significant association between $I G F 1 R$ expression and biochemical recurrence (Supplementary Figure S1E). However, as noted previously, we found only borderline association of biochemical recurrence and total IGF$1 \mathrm{R}$ in the radiotherapy cohort (Table 3; Supplementary Figure $\mathrm{S} 1 \mathrm{C}$ ), and we are comparing semi-quantitative IHC scores with microarray analysis of IGF1R mRNA. Therefore, it will be important to assess the prognostic significance of IGF-1R at the protein level in a surgically treated cohort, to enable a more robust comparison.

\section{DISCUSSION}

The major findings of our study are the identification of significant associations between total IGF-1R and risk of overall and 


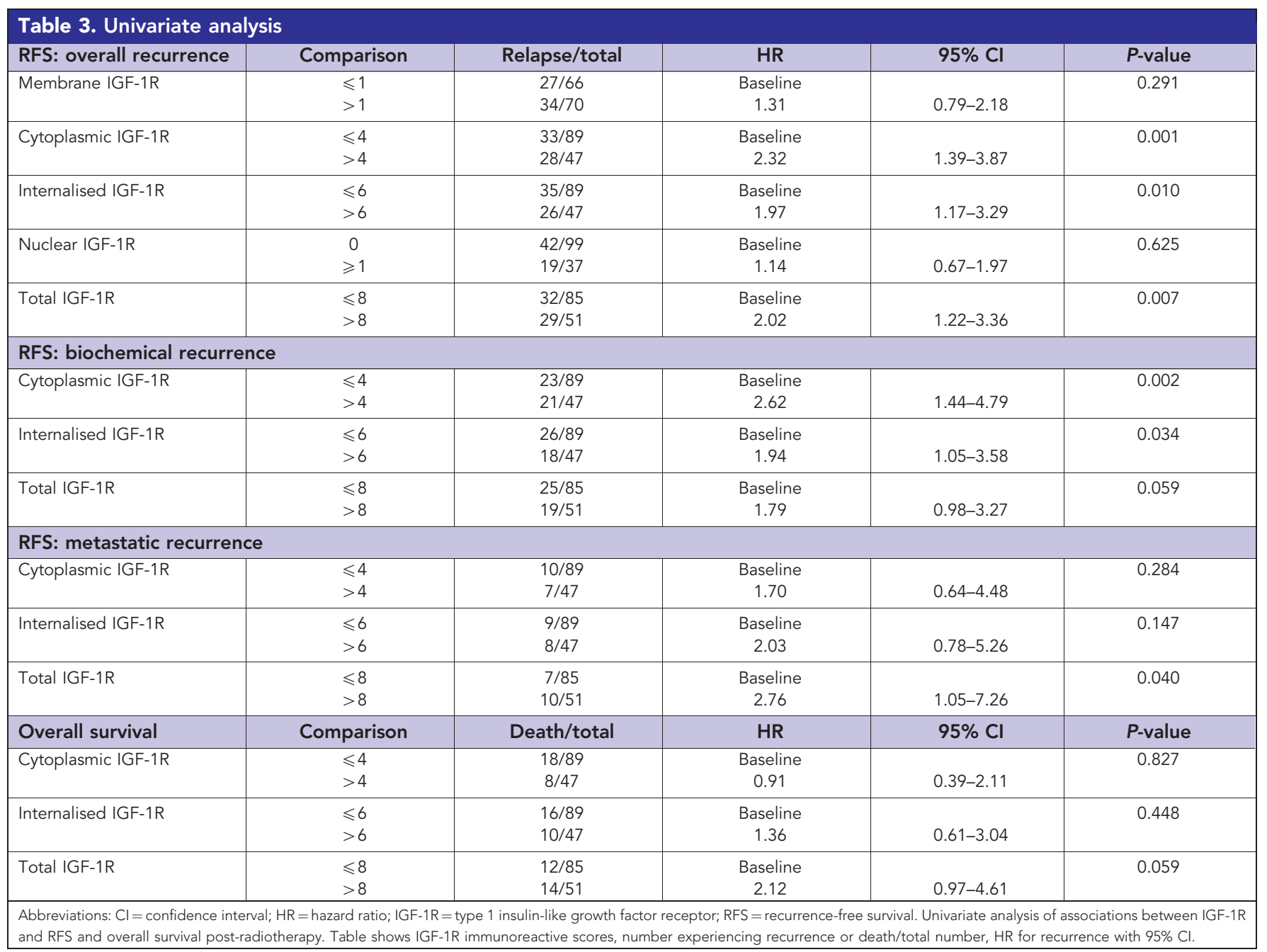

metastatic recurrence, and between cytoplasmic or internalised IGF-1R and biochemical recurrence, following radical radiotherapy but not surgery for prostate cancer. These associations were revealed by univariate and Kaplan-Meier analyses; multivariate analysis also indicated that cytoplasmic IGF-1R is an independent predictor of biochemical recurrence. Most of the patients in our series were treated pre-2006 and received radiotherapy at $55 \mathrm{~Gy}$ in 20 fractions, equivalent to $65.9 \mathrm{~Gy}$ in $2 \mathrm{~Gy}$ fractions. Although this seems a modest dose by current standards, this dose/fractionation schedule was widely used in the United Kingdom during the era in which these patients were treated. It remains to be seen whether IGF-1R retains predictive significance in patients treated at 74 Gy in 37 fractions as is current practice, or the biologically equivalent hypo-fractionated dose of $60 \mathrm{~Gy}$ in $3 \mathrm{~Gy}$ fractions (Dearnaley et al, 2014, 2016). Forty-two percent of patients in our series had received adjuvant endocrine therapy. This is relevant, given known crosstalk between IGF-1R, androgen receptor signalling and the DNA damage response, and reports that anti-androgen therapy enhances prostate cancer radiosensitivity in preclinical models and clinically (Pandini et al, 2005; Kumar et al, 2006; Bolla et al, 2010; Goodwin et al, 2013; Polkinghorn and Zelefsky, 2013; Zelefsky et al, 2013). In the current study, we found no evidence of better outcomes in the group receiving endocrine therapy, likely because this had been offered only to high-risk patients. It is possible that the use of adjuvant endocrine therapy in a subset of patients could have influenced the associations we found between IGF-1R and clinical outcomes.
In probing the relevance of IGF-1R subcellular localisation, we noted that the association of cytoplasmic or internalised IGF-1R with biochemical recurrence was stronger than for total IGF-1R. Type 1 IGF receptor internalisation is required for prolonged AKT activation (Romanelli et al, 2007), and for IGF-1R nuclear translocation, which contributes to IGF axis activity by promoting gene expression (Aleksic et al, 2010; Sehat et al, 2010; Sarfstein et al, 2012; Warsito et al, 2012). The lack of significant association with nuclear IGF-1R alone, and the stronger association of cytoplasmic IGF-1R than internalised (nuclear plus cytoplasmic) IGF-1R with overall and biochemical recurrence (Table 3) suggest that cytoplasmic IGF-1R is the major contributor here. Supporting this view, cytoplasmic IGF-1R was an independent predictor of biochemical recurrence in multivariate analysis (Table 4). Therefore, it is plausible that the association of biochemical recurrence with cytoplasmic IGF-1R could reflect increased IGF-1R activation in radioresistant tumours. This would be consistent with data we reported in cell lines, where suppression of IGF-1R activity enhanced radiosensitivity (Turney et al, 2012; Chitnis et al, 2014). In patients with PSA-detected localised prostate cancer, radiotherapy and surgery are reported to lead to comparable outcomes at median 10 years' follow-up (Hamdy et al, 2016). Several predictive biomarkers have been identified to predict outcomes post irradiation for prostate cancer (Wilkins et al, 2015), but a role for IGF-1R has not previously been highlighted in this context. Our data suggest that patients whose prostate cancers contain high cytoplasmic or 


\begin{tabular}{|c|c|c|c|c|}
\hline & Comparison & HR & $95 \% \mathrm{Cl}$ & $P$-value \\
\hline \multicolumn{5}{|l|}{ RFS: all recurrence } \\
\hline Cytoplasmic IGF-1R & $\begin{array}{l}\leqslant 4 \\
>4\end{array}$ & $\begin{array}{l}\text { Baseline } \\
2.05\end{array}$ & $1.21-3.45$ & 0.007 \\
\hline Stage & $\begin{array}{l}\text { CT1 } \\
\text { cT2 } \\
\text { cT3 }\end{array}$ & $\begin{array}{l}\text { Baseline } \\
2.61 \\
1.84\end{array}$ & $\begin{array}{l}1.33-5.11 \\
0.81-4.19\end{array}$ & $\begin{array}{l}0.005 \\
0.145\end{array}$ \\
\hline $\begin{array}{l}\text { Primary Gleason } \\
\text { grade }\end{array}$ & $\begin{array}{l}3 \\
\geqslant 4\end{array}$ & $\begin{array}{l}\text { Baseline } \\
1.56\end{array}$ & $0.91-2.68$ & 0.108 \\
\hline \multicolumn{5}{|l|}{ RFS: all recurrence } \\
\hline Internalised IGF-1R & $\begin{array}{l}\leqslant 6 \\
>6\end{array}$ & 1.75 & $1.04-2.97$ & 0.036 \\
\hline Stage & $\begin{array}{l}\text { CT1 } \\
\text { cT2 } \\
\text { cT3 }\end{array}$ & $\begin{array}{l}\text { Baseline } \\
2.76 \\
1.90\end{array}$ & $\begin{array}{l}1.40-5.42 \\
0.72-4.34\end{array}$ & $\begin{array}{l}0.003 \\
0.130\end{array}$ \\
\hline $\begin{array}{l}\text { Primary Gleason } \\
\text { grade }\end{array}$ & $\begin{array}{l}3 \\
\geqslant 4\end{array}$ & $\begin{array}{l}\text { Baseline } \\
1.49\end{array}$ & $0.86-2.56$ & 0.155 \\
\hline \multicolumn{5}{|l|}{ RFS: all recurrence } \\
\hline Total IGF-1R & $\begin{array}{l}\leqslant 8 \\
>8\end{array}$ & $\begin{array}{l}\text { Baseline } \\
1.77\end{array}$ & $1.04-3.02$ & 0.037 \\
\hline Stage & $\begin{array}{l}\text { cT1 } \\
\text { cT2 } \\
\text { cT3 }\end{array}$ & $\begin{array}{l}\text { Baseline } \\
2.88 \\
1.87\end{array}$ & $\begin{array}{l}1.47-5.65 \\
0.82-4.26\end{array}$ & $\begin{array}{l}0.002 \\
0.136\end{array}$ \\
\hline $\begin{array}{l}\text { Primary Gleason } \\
\text { grade }\end{array}$ & $\begin{array}{c}3 \\
\geqslant 4\end{array}$ & $\begin{array}{l}\text { Baseline } \\
1.33\end{array}$ & $0.76-2.34$ & 0.315 \\
\hline \multicolumn{5}{|c|}{ RFS: biochemical recurrence } \\
\hline Cytoplasmic IGF-1R & $\begin{array}{l}\leqslant 4 \\
>4\end{array}$ & $\begin{array}{l}\text { Baseline } \\
2.29\end{array}$ & $1.23-4.26$ & 0.009 \\
\hline Stage & $\begin{array}{l}\text { cT1 } \\
\text { cT2 } \\
\text { cT3 }\end{array}$ & $\begin{array}{l}\text { Baseline } \\
2.62 \\
2.01\end{array}$ & $\begin{array}{l}1.19-5.74 \\
0.76-5.32\end{array}$ & $\begin{array}{l}0.016 \\
0.160\end{array}$ \\
\hline $\begin{array}{l}\text { Primary Gleason } \\
\text { grade }\end{array}$ & $\begin{array}{l}3 \\
\geqslant 4\end{array}$ & $\begin{array}{l}\text { Baseline } \\
1.12\end{array}$ & $0.59-2.13$ & 0.729 \\
\hline $\begin{array}{l}\text { Abbreviations: } \mathrm{Cl}=\text { conf } \\
\text { growth factor receptor; } \\
\text { factors showing indepen }\end{array}$ & $\begin{array}{l}\text { interval; } \mathrm{HF} \\
\text { recurrence-ff } \\
\text { sociation wit }\end{array}$ & $\begin{array}{l}\text { zard rati } \\
\text { rival. N }\end{array}$ & $\begin{array}{l}\mathrm{F}-1 \mathrm{R}=\text { type } 1 \\
\text { ariate analysis } \\
\text { post radiother }\end{array}$ & $\begin{array}{l}\text { insulin-like } \\
\text { to identify } \\
\text { apy. }\end{array}$ \\
\hline
\end{tabular}

high total IGF-1R should be offered surgery or dose-escalated radiotherapy, hypotheses that warrant prospective evaluation. Taken together with preclinical data (Isebaert et al, 2011; Turney et al, 2012; Chitnis et al, 2014), these results also support evaluation of IGF axis inhibition as a novel route to radiosensitisation of prostate cancers that express high total or cytoplasmic IGF-1R.

\section{ACKNOWLEDGEMENTS}

This work was supported by Prostate Cancer UK (grant G2012/25), Development Fund of Cancer Research UK Oxford Cancer Research Centre (CRUKDF 0715-VMTA and OCRC0612VM), UCARE-Oxford (TA/VM-2016), National Institute for Health Research (NIHR) Research Capacity Funding (AC14/037) and support to VMM from the NIHR Oxford Biomedical Research Centre. We are very grateful to the patients who consented to use of tumour tissue in research. We are also grateful for help with clinical data from Tristan Crumpton, and comments on the manuscript from Guillaume Rieunier.

\section{CONFLICT OF INTEREST}

The authors declare no conflict of interest.

\section{AUTHOR CONTRIBUTIONS}

VMM and TA planned the study; DC treated the patients; RJB, ARW, LB, SL, GSH, FF and AS collected the clinical data; TA and $\mathrm{CV}$ performed and scored IHC; $\mathrm{CH}$ and VMM analysed IHC data; $\mathrm{SH}$ and FMB analysed gene expression data; and VMM wrote the manuscript. All authors approved the final version of the manuscript.

\section{REFERENCES}

Aleksic T, Chitnis MM, Perestenko OV, Gao S, Thomas PH, Turner GD, Protheroe AS, Howarth M, Macaulay VM (2010) Type 1 insulin-like growth factor receptor translocates to the nucleus of human tumor cells. Cancer Res 70: 6412-6419.

Aleksic T, Worrall AR, Verrill C, Turley H, Campo L, Macaulay VM (2016) Improved immunohistochemical detection of type 1 insulin-like growth factor receptor in human tumors. Immunochem Immunopathol 2: 114 .

Baker J, Liu JP, Robertson EJ, Efstratiadis A (1993) Role of insulin-like growth factors in embryonic and postnatal growth. Cell 75: 73-82.

Bolla M, Van Tienhoven G, Warde P, Dubois JB, Mirimanoff RO, Storme G, Bernier J, Kuten A, Sternberg C, Billiet I, Torecilla JL, Pfeffer R, Cutajar CL, Van Der Kwast T, Collette L (2010) External irradiation with or without long-term androgen suppression for prostate cancer with high metastatic risk: 10-year results of an EORTC randomised study. Lancet Oncol 11: 1066-1073.

Chitnis MM, Lodhia KA, Aleksic T, Gao S, Protheroe AS, Macaulay VM (2014) IGF-1R inhibition enhances radiosensitivity and delays double-strand break repair by both non-homologous end-joining and homologous recombination. Oncogene 33: 5262-5273.

Chitnis MM, Yuen JS, Protheroe AS, Pollak M, Macaulay VM (2008) The type 1 insulin-like growth factor receptor pathway. Clin Cancer Res 14: 6364-6370.

Cosaceanu D, Budiu RA, Carapancea M, Castro J, Lewensohn R, Dricu A (2007) Ionizing radiation activates IGF-1R triggering a cytoprotective signaling by interfering with Ku-DNA binding and by modulating Ku86 expression via a p38 kinase-dependent mechanism. Oncogene 26: 2423-2434.

Dale OT, Aleksic T, Shah KA, Han C, Mehanna H, Rapozo DC, Sheard JD, Goodyear P, Upile NS, Robinson M, Jones TM, Winter S, Macaulay VM (2015) IGF-1R expression is associated with HPV-negative status and adverse survival in head and neck squamous cell cancer. Carcinogenesis 36: 648-655.

Dearnaley D, Syndikus I, Mossop H, Khoo V, Birtle A, Bloomfield D, Graham J, Kirkbride P, Logue J, Malik Z, Money-Kyrle J, O'sullivan JM, Panades M, Parker C, Patterson H, Scrase C, Staffurth J, Stockdale A, Tremlett J, Bidmead M, Mayles H, Naismith O, South C, Gao A, Cruickshank C, Hassan S, Pugh J, Griffin C, Hall E. Investigators, CH (2016) Conventional versus hypofractionated high-dose intensitymodulated radiotherapy for prostate cancer: 5-year outcomes of the randomised, non-inferiority, phase $3 \mathrm{CHHiP}$ trial. Lancet Oncol 17: 1047-1060.

Dearnaley DP, Jovic G, Syndikus I, Khoo V, Cowan RA, Graham JD, Aird EG, Bottomley D, Huddart RA, Jose CC, Matthews JH, Millar JL, Murphy C, Russell JM, Scrase CD, Parmar MK, Sydes MR (2014) Escalated-dose versus control-dose conformal radiotherapy for prostate cancer: long-term results from the MRC RT01 randomised controlled trial. Lancet Oncol 15: 464-473.

Gabriele D, Jereczek-Fossa BA, Krengli M, Garibaldi E, Tessa M, Moro G, Girelli G, Gabriele P, Consortium, E (2016) Beyond D'Amico risk classes for predicting recurrence after external beam radiotherapy for prostate cancer: the Candiolo classifier. Radiat Oncol 11: 23.

Goh LK, Sorkin A (2013) Endocytosis of receptor tyrosine kinases. Cold Spring Harb Perspect Biol 5: a017459. 
Goodwin JF, Schiewer MJ, Dean JL, Schrecengost RS, De Leeuw R, Han S, Ma T, Den RB, Dicker AP, Feng FY, Knudsen KE (2013) A hormoneDNA repair circuit governs the response to genotoxic insult. Cancer Discov 3: 1254-1271.

Grossfeld GD, Latini DM, Lubeck DP, Broering JM, Li YP, Mehta SS, Carroll PR (2002) Predicting disease recurrence in intermediate and high-risk patients undergoing radical prostatectomy using percent positive biopsies: results from CaPSURE. Urology 59: 560-565.

Hamdy FC, Donovan JL, Lane JA, Mason M, Metcalfe C, Holding P, Davis M, Peters TJ, Turner EL, Martin RM, Oxley J, Robinson M, Staffurth J, Walsh E, Bollina P, Catto J, Doble A, Doherty A, Gillatt D, Kockelbergh R, Kynaston H, Paul A, Powell P, Prescott S, Rosario DJ, Rowe E, Neal DE, Group, PS (2016) 10-year outcomes after monitoring, surgery, or radiotherapy for localized prostate cancer. N Engl J Med 375: 1415-1424.

Heidenreich A, Bastian PJ, Bellmunt J, Bolla M, Joniau S, Van Der Kwast T, Mason M, Matveev V, Wiegel T, Zattoni F, Mottet N, European Association Of, U (2014) EAU guidelines on prostate cancer. part 1: screening, diagnosis, and local treatment with curative intent-update 2013. Eur Urol 65: 124-137.

Hellawell GO, Turner GD, Davies DR, Poulsom R, Brewster SF, Macaulay VM (2002) Expression of the type 1 insulin-like growth factor receptor is up-regulated in primary prostate cancer and commonly persists in metastatic disease. Cancer Res 62: 2942-2950.

Isebaert SF, Swinnen JV, Mcbride WH, Haustermans KM (2011) Insulin-like growth factor-type 1 receptor inhibitor NVP-AEW541 enhances radiosensitivity of PTEN wild-type but not PTEN-deficient human prostate cancer cells. Int J Radiat Oncol Biol Phys 81: 239-247.

King H, Aleksic T, Haluska P, Macaulay VM (2014) Can we unlock the potential of IGF-1R inhibition in cancer therapy? Cancer Treat Rev 40: 1096-1105.

Kumar S, Shelley M, Harrison C, Coles B, Wilt TJ, Mason MD (2006) Neoadjuvant and adjuvant hormone therapy for localised and locally advanced prostate cancer. Cochrane Database Syst Rev: CD006019.

Lloret M, Lara PC, Bordon E, Pinar B, Rey A, Falcon O, Molano F, Hernandez MA (2007) IGF-1R expression in localized cervical carcinoma patients treated by radiochemotherapy. Gynecol Oncol 106: 8-11.

Macaulay VM, Salisbury AJ, Bohula EA, Playford MP, Smorodinsky NI, Shiloh Y (2001) Downregulation of the type 1 insulin-like growth factor receptor in mouse melanoma cells is associated with enhanced radiosensitivity and impaired activation of Atm kinase. Oncogene 20: 4029-4040.

Morgan PB, Hanlon AL, Horwitz EM, Buyyounouski MK, Uzzo RG, Pollack A (2007) Timing of biochemical failure and distant metastatic disease for low-, intermediate-, and high-risk prostate cancer after radiotherapy. Cancer 110: 68-80.

Pandini G, Mineo R, Frasca F, Roberts Jr CT, Marcelli M, Vigneri R, Belfiore A (2005) Androgens up-regulate the insulin-like growth factor-I receptor in prostate cancer cells. Cancer Res 65: 1849-1857.

Polkinghorn WR, Zelefsky MJ (2013) Improving outcomes in high-risk prostate cancer with radiotherapy. Rep Pract Oncol Radiother 18: 333-337.

Riesterer O, Yang Q, Raju U, Torres M, Molkentine D, Patel N, Valdecanas D, Milas L, Ang KK (2011) Combination of anti-IGF-1R antibody A12 and ionizing radiation in upper respiratory tract cancers. Int J Radiat Oncol Biol Phys 79: 1179-1187.

Roach 3rd M, Hanks G, Thames Jr H, Schellhammer P, Shipley WU, Sokol GH, Sandler H (2006) Defining biochemical failure following radiotherapy with or without hormonal therapy in men with clinically localized prostate cancer: recommendations of the RTOG-ASTRO Phoenix Consensus Conference. Int J Radiat Oncol Biol Phys 65: 965-974.

Romanelli RJ, Lebeau AP, Fulmer CG, Lazzarino DA, Hochberg A, Wood TL (2007) Insulin-like growth factor type-I receptor internalization and recycling mediate the sustained phosphorylation of Akt. J Biol Chem 282: 22513-22524.

Sarfstein R, Pasmanik-Chor M, Yeheskel A, Edry L, Shomron N, Warman N, Wertheimer E, Maor S, Shochat L, Werner H (2012) Insulin-like growth factor-I receptor (IGF-IR) translocates to nucleus and autoregulates IGF-IR gene expression in breast cancer cells. J Biol Chem 287: 2766-2776.

Sehat B, Tofigh A, Lin Y, Trocme E, Liljedahl U, Lagergren J, Larsson O (2010) SUMOylation mediates the nuclear translocation and signaling of the IGF-1 receptor. Sci Signal 3: ra10.

Taylor BS, Schultz N, Hieronymus H, Gopalan A, Xiao Y, Carver BS, Arora VK, Kaushik P, Cerami E, Reva B, Antipin Y, Mitsiades N, Landers T, Dolgalev I, Major JE, Wilson M, Socci ND, Lash AE, Heguy A, Eastham JA, Scher HI, Reuter VE, Scardino PT, Sander C, Sawyers CL, Gerald WL (2010) Integrative genomic profiling of human prostate cancer. Cancer Cell 18: 11-22.

Tezuka M, Watanabe H, Nakamura S, Yu D, Aung W, Sasaki T, Shibuya H, Miura M (2001) Antiapoptotic activity is dispensable for insulin-like growth factor I receptor-mediated clonogenic radioresistance after gamma-irradiation. Clin Cancer Res 7: 3206-3214.

Turner BC, Haffty BG, Narayanan L, Yuan J, Havre PA, Gumbs AA, Kaplan L, Burgaud JL, Carter D, Baserga R, Glazer PM (1997) Insulin-like growth factor-I receptor overexpression mediates cellular radioresistance and local breast cancer recurrence after lumpectomy and radiation. Cancer Res 57: 3079-3083.

Turney BW, Kerr M, Chitnis MM, Lodhia K, Wang Y, Riedemann J, Rochester M, Protheroe AS, Brewster SF, Macaulay VM (2012) Depletion of the type 1 IGF receptor delays repair of radiation-induced DNA double strand breaks. Radiother Oncol 103: 402-409.

Warsito D, Sjostrom S, Andersson S, Larsson O, Sehat B (2012) Nuclear IGF1R is a transcriptional co-activator of LEF1/TCF. EMBO Rep 13: 244-250.

Wilkins A, Dearnaley D, Somaiah N (2015) Genomic and histopathological tissue biomarkers that predict radiotherapy response in localised prostate cancer. Biomed Res Int 2015: 238757.

Zargar H, Lamb AD, Rocco B, Porpiglia F, Liatsikos E, Davis J, Coelho RF, Pow-Sang JM, Patel VR, Murphy DG (2017) Salvage robotic prostatectomy for radio recurrent prostate cancer: technical challenges and outcome analysis. Minerva Urol Nefrol 69: 26-37.

Zelefsky MJ, Gomez DR, Polkinghorn WR, Pei X, Kollmeier M (2013) Biochemical response to androgen deprivation therapy before external beam radiation therapy predicts long-term prostate cancer survival outcomes. Int J Radiat Oncol Biol Phys 86: 529-533.

This work is published under the standard license to publish agreement. After 12 months the work will become freely available and the license terms will switch to a Creative Commons AttributionNonCommercial-Share Alike 4.0 Unported License.

Supplementary Information accompanies this paper on British Journal of Cancer website (http://www.nature.com/bjc) 